\title{
SKIN METASTASIS FROM BASE OF TONGUE CARCINOMA AT PRESENTATION - A RARE CASE REPORT
}

Subrata Chattopadhyay ${ }^{1}$, Anindya Mukherjee ${ }^{2}$, Aramita Saha ${ }^{3}$, Mohammad Azam ${ }^{4}$

\section{HOW TO CITE THIS ARTICLE:}

Subrata Chattopadhyay, Anindya Mukherjee, Aramita Saha, Mohammad Azam. "Skin metastasis from base of tongue carcinoma at presentation - a rare case report". Journal of Evolution of Medical and Dental Sciences 2013; Vol2, Issue 29, July 22; Page: 5323-5326.

ABSTRACT: Traditionally considered to be a loco-regional disease, head neck cancers metastasize infrequently to distant sites. Among these, skin metastases have been rarely reported and almost always they have been encountered during or after treatment of primary. We present here a case of squamous cell carcinoma of base of tongue with multiple dermal metastases at initial presentation. This report signifies that rarity of such cases must not delay the confirmation of diagnosis since these patients already carry a dismal prognosis.

KEYWORDS: Squamous cell carcinoma, base of tongue, skin metastasis, rare.

INTRODUCTION: Distant metastases from head neck squamous cell carcinomas (SCCs) in general and SCC of tongue in particular have been commonly observed to be in lungs $(66 \%)$ followed by bones(22\%) and liver(10\%) [1, 2,3,4].The incidence of cutaneous metastases from HNSCC has been reported to be less than 1\% [5]. To the best of our knowledge, SCC of base of tongue with local and distant, i.e, skin metastases occurring simultaneously as initial presentation is the first case to be reported till date.

CASE HISTORY: A 53 year old male from a Midnapore district of West Bengal visited our clinic in March, 2013 with complaints of severe dysphagia due to bulky neck swellings and multiple nodular swellings on the skin over abdomen [figure 1]. Difficulty in swallowing due to mass felt at the back of tongue was the first complaint 2 months back. The neck swellings appeared one and a half month back and had progressed rapidly to the present size. The nodules over the abdomen were detected only a month back. Other than a history of heavy smoking for the last 30 years, there were no other forms of addiction. He was neither diabetic, nor hypertensive and had a ECOG performance of ' 2 '.

Clinical examination and contrast enhanced CT scan of neck revealed irregular hard mass in base of tongue eroding into left retromolar trigone and hard bilateral neck nodes with the largest one measuring $5.4 \mathrm{X} 6.2 \mathrm{~cm}$.A specimen from the tongue mass showed grade 2 (moderately differentiated) squamous cell carcinoma with peri-neural invasion but no lympho-vascular tumor emboli was detected. Punch Biopsy from a skin nodule revealed metastatic squamous cell carcinoma deposits. Metastatic work-up revealed no other sites of metastasis. Routine investigations were essentially normal. The disease was staged to be cT4aN3M1.

Salvage chemotherapy with Docetaxel $(80 \mathrm{mg} / \mathrm{m} 2$ on day 1$)$, cisplatin $(75 \mathrm{mg} / \mathrm{m} 2$ on day 1$)$ and 5-Flurouracil $(1000 \mathrm{mg} / \mathrm{m} 2$ day1-4) was initiated within a week and he has tolerated well two such cycles so far. A partial response of the primary and neck nodes has been documented and the skin nodules have completely disappeared [figure 2]. 
DISCUSSION: Oral and pharyngeal cancer, grouped together, is the sixth most common cancer in the world [6]. Some countries with the highest incidence rates for oral and oropharyngeal cancer in the world are located in the region of South Asia[6].Urban cancer registries of India identify rates of oropharyngeal cancer as between 3.4 and 6.0 per 100,000 [7].

In an analysis of metastatic patterns from squamous cell carcinomas of head and neck, Kotwall et al reported hypopharynx to be the commonest primary site(60\%), followed by base of tongue(53\%) and anterior tongue(50\%) ${ }^{[8]}$.The tumor site, stage of the disease, lymph nodal status, type of treatment(surgery, concurrent chemo-radiotherapy and radiotherapy alone or postoperatively), decade of presentation have been considered to be predictive factors for distant metastasis from oral and oro-pharyngeal SCCs ${ }^{[9]}$.Achievement of local control also decided the occurrence of distant failures. Additionally, extra-capsular extension of tumor and presence of more than two visceral metastases have been reported by Pitman et al[5] to specially impact the incidence of cutaneous metastasis. Most of these poor prognostic determinants were present with our patient. However, the fact that the skin nodules appeared shortly after the neck swellings started increasing in size is rather unique because most of the cases of skin metastases so far reported have occurred after the completion of definitive therapy. It clearly proves the unusually aggressive nature of this tumor.

Skin metastases from tongue or oropharyngeal or tongue primaries are exceedingly rare, with only a few case reports till date. Dasmajumdar[10] and Walvekar[11] cited tonsillar primaries with nodular skin metastasis while Osborne[12] and Longo[13] reported cases of dermal metastasis from tongue carcinoma. They may be solitary or multiple, discrete or confluent and usually spare the epidermis. Distant spread by haematogenous route is implicated in this case. Skin metastases are usually located in supra-diaphragmatic location, most commonly in face, scalp, lips, chest, axilla and arms. Involvement of nearly whole of the abdominal skin sparing the usual sites is unique to this case.

The development of skin metastases portends a very poor prognosis with a median survival of only 3 months (range-1-16 months) following diagnosis [5].Surgery is not recommended and treatment is essentially palliative. Chemotherapy is the standard of care as initiated in this case. Radiotherapy has not been shown to be of much benefit and is not standardized yet. This case presented here upholds the importance of being vigilant about identifying skin metastases owing to its poor prognosis. Confusing it with infectious or inflammatory process would only delay the diagnosis for the worse.

\section{REFERENCES:}

1. Merino OR, Lindberg RD, Fletcher GH: analysis of distant metastases from squamous cell carcinoma of the upper respiratory and digestive tracts. Cancer 1977; 40:145-151.

2. Leon X, Quer M, Orus C, Del Prado Venegas M, Lopez M: Distant metastases in head and neck cancer patients who achieved loco-regional control. Head Neck 2000; 22:680-686.

3. Strong EW: Carcinoma of the tongue. Otolaryngol Clin North Am 12:107-114, 1979.

4. Foote RL, Olson KD, Davis DL, et al: Base of tongue carcinoma: Patterns of failure and predictors of recurrence after surgery alone. Head Neck 15:300-307, 1993

5. Pitman KT, Johnson JT. Skin metastases from head and neck squamous cell carcinoma: incidence and impact. Head Neck 1999; 21(6): 560-565. 
6. Saman Warnakulasuriya. Review .Global epidemiology of oral and oropharyngeal cancer. Oral Oncology 45 (2009) 309-316.

7. DM Parkin, F Bray, J Ferlay. Global cancer Statistics, 2002. CA: A Cancer journal for clinicians 2005; 55: 74-108

8. Kotwall C, Sako K, RazackMS, Rao U, et al. Metastatic patterns in squamous cell cancer of the head and neck. Am J Surg 1987; 154: 439- 442.

9. Kowalski LP, Carvalho AL, Martins Priante AV, Magrin J: Predictive factors for distant metastasis from oral and oropharyngeal squamous cell carcinoma. Oral Oncol2005, 41:534541.

10. Dasmajumdar SK, Gairola M, Sharma DN, Mohanti BK. Cutaneous metastasis from carcinoma of tonsil. J Postgrad Med [serial online] 2002 [cited 2006 Oct 17]; 48:32-3. Available from:http://www.jpgmonline.com/article.asp?issn=0022-3859; year=2002; $\quad$ volume=48; issue $=1$; spage $=32$; epage $=3$; aulast $=$ Dasmajumdar .

11. Walvekar RR, Chaukar DA, Mahajan A, D'Cruz AK. Skin Metastasis in an Oropharyngeal Cancer- Report of a case and review of literature. Bombay Hospital Journal 2006 January; 48(1): 175-178.

12. Osborne RF. Case report: Dermal metastasis from visceral primary. Ear, Nose Throat J 2004July; 83(7):432.

13. Raffaele Longo, Francesco Torino, Mariangela Castellana et al. Skin Acro metastases in Squamous Cell Carcinoma of the Tongue. J Clin Oncol 25:2847-2848, 2007.

\section{Before Treatment:}

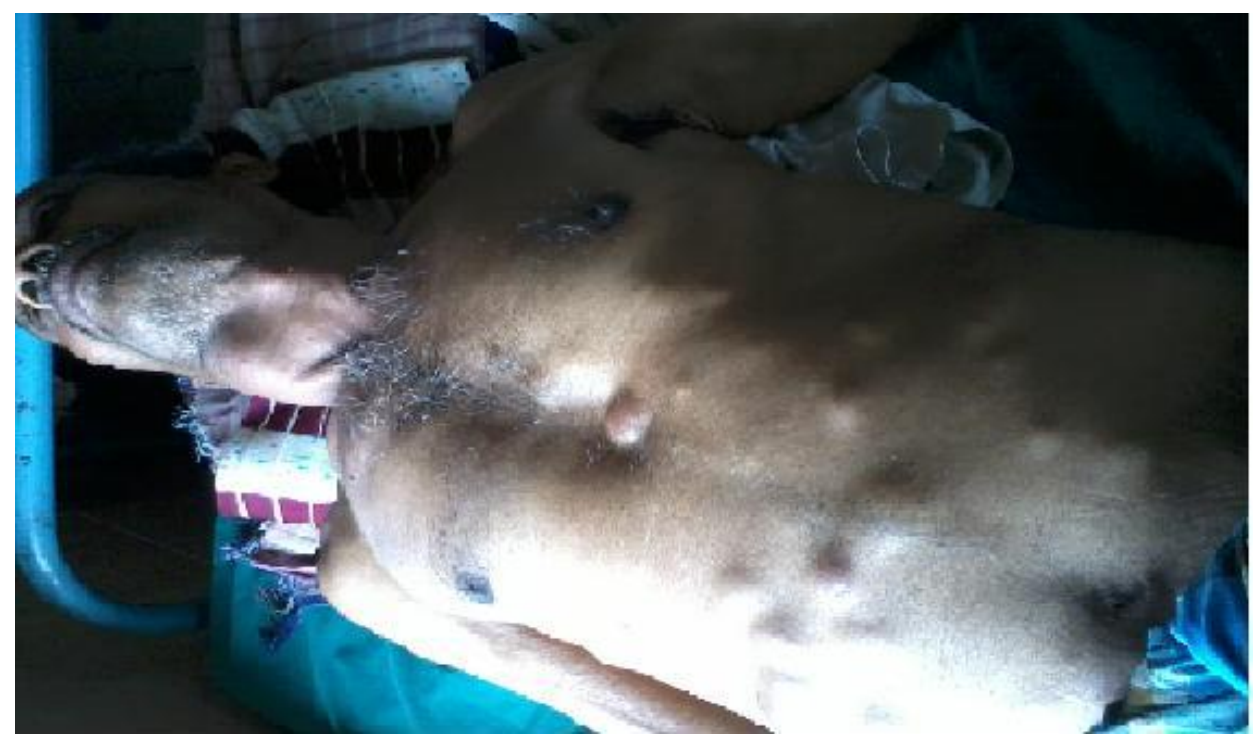




\section{CASE REPORT}

\section{After Treatment:}

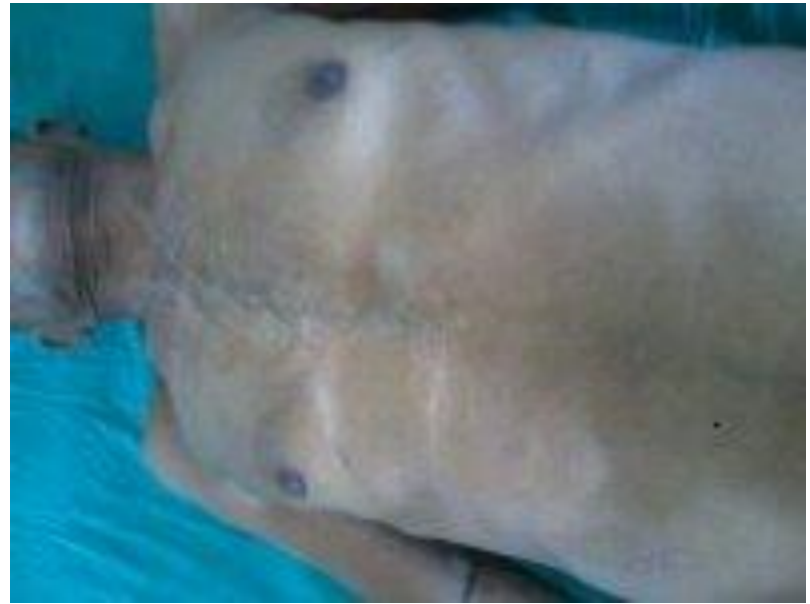

\section{AUTHORS:}

1. Subrata Chattopadhyay

2. Anindya Mukherjee

3. Aramita Saha

4. Mohammad Azam

\section{PARTICULARS OF CONTRIBUTORS:}

1. Assistant Professor, Department of Radiotherapy, Medical College, Kolkata.

2. Post-graduate Trainee, Department of Radiotherapy, Medical College, Kolkata.

3. Ex-Post - Graduate Trainee, Department of Radiotherapy, Medical college, Kolkata.

Presently acting as Senior resident, Department of Medical Oncology, Apollo Gleangles Hospital, Kolkata.

4. Post-Graduate Trainee, Dept. of Radiotherapy, Medical College, Kolkata.

\section{NAME ADRRESS EMAIL ID OF THE} CORRESPONDING AUTHOR:

Dr. Subrata Chattopadhyay, Department of Radiation Oncology, Orbit sky View, Block-IV, Flat-10C, 1/1A, UmakantaSen lane, Kolkata-700030 Email-chatterjeesubrat@gmail.com

Date of Submission: 15/06/2013. Date of Peer Review: 16/06/2013. Date of Acceptance: 08/07/2013. Date of Publishing: 17/07/2013 